\title{
An Aerial Radiological Survey of the Portsmouth Gaseous Diffusion Plant and Surrounding Area
}

\author{
Portsmouth, Ohio
}




\section{DISCLAIMER}

This report was prepared as an account of work sponsored by an agency of the U.S. Government. Neither the U.S. Government nor any agency thereof, nor any of their employees, nor any of their contractors, subcontractors or their employees, makes any warranty or representation, express or implied, or assumes any legal liability or responsibility for the accuracy, completeness, or usefulness of any information, apparatus, product, or process disclosed, or represents that its use would not infringe privately owned rights. Reference herein to any specific commercial product, process, or service by trade name, trademark, manufacturer, or otherwise, does not necessarily constitute or imply its endorsement, recommendation, or favoring by the U.S. Government or any agency thereof. The views and opinions of authors expressed herein do not necessarily state or reflect those of the U.S. Government or any agency thereof. 


\title{
An Aerial Radiological Survey of the Portsmouth Gaseous Diffusion Plant and Surrounding Area
}

\section{Portsmouth, Ohio}

\author{
Namdoo Moon \\ Project Scientist \\ National Security Technologies, LLC \\ Las Vegas, Nevada
}

Survey Dates - August 7-8, 2007

This document is UNCLASSIFIED

Reviewed by

Valerie Ward, October 9, 2007

Derivative Classifier 


\section{ABSTRACT}

An aerial radiological survey was conducted over the 16 square-mile ( $\sim 1$ square-kilometer) area surrounding the Portsmouth Gaseous Diffusion Plant. The survey was performed in August 2007 utilizing a large array of helicopter mounted sodium iodide detectors. The purpose of the survey was to update the previous radiological survey levels of the environment and surrounding areas of the plant. A search for a missing radium-226 source was also performed.

Implied exposure rates, man-made activity, and excess bismuth-214 activity, as calculated from the aerial data are presented in the form of isopleth maps superimposed on imagery of the surveyed area. Ground level and implied aerial exposure rates for nine specific locations are compared.

Detected radioisotopes and their associated gamma ray exposure rates were consistent with those expected from normal background emitters. At specific plant locations described in the report, manmade activity was consistent with the operational histories of the location. There was no spectral activity that would indicate the presence of the lost source. 


\section{TABLE OF CONTENTS}

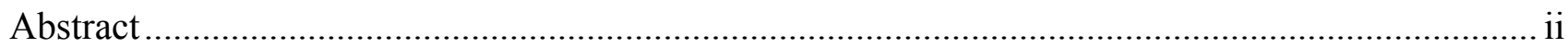

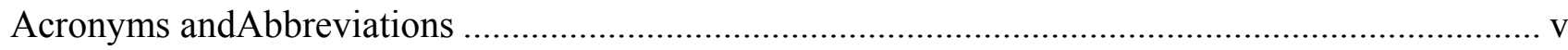

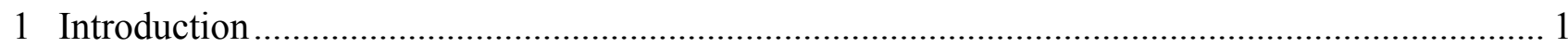

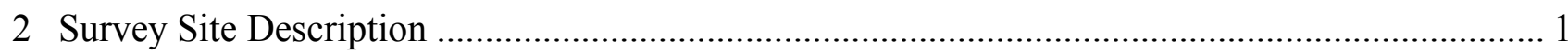

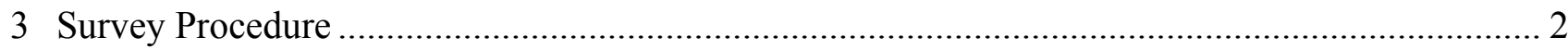

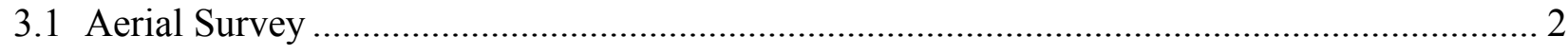

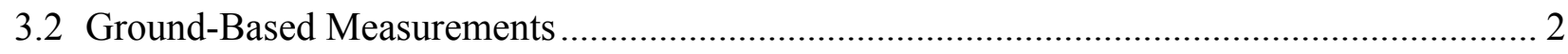

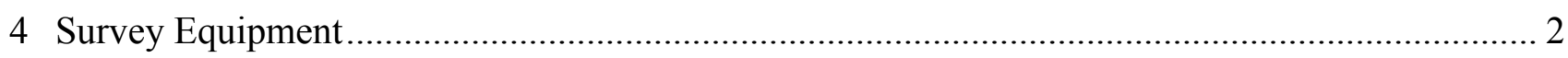

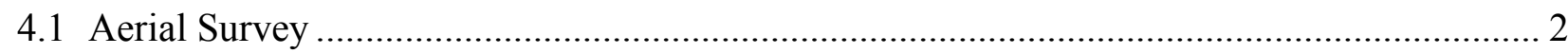

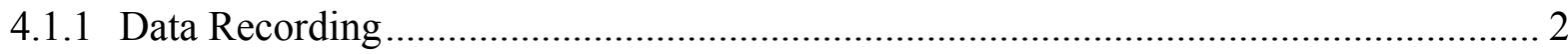

4.1.2 Helicopter Positioning ...................................................................................... 3

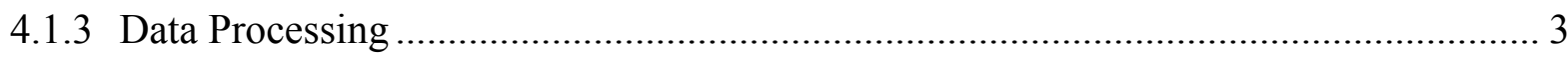

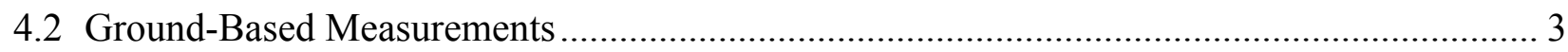

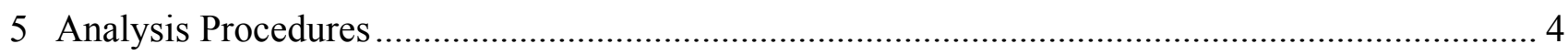

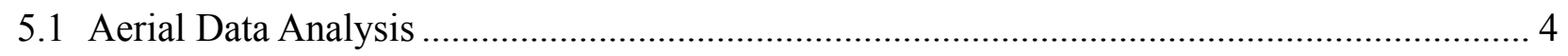

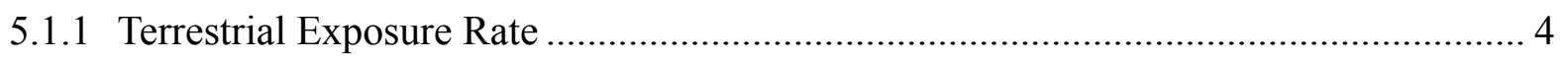

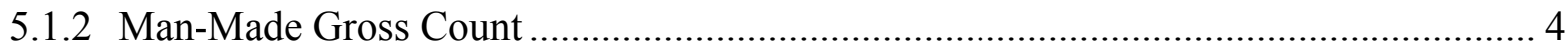

5.1.3 Radium-Specific Isotope Extraction Algorithm ..................................................... 5

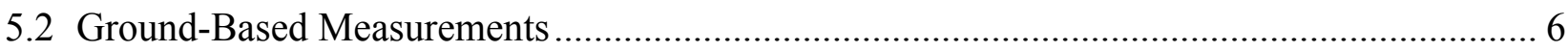

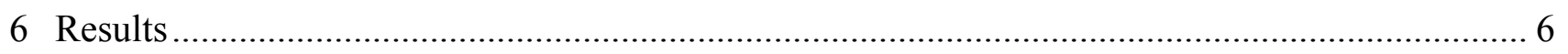

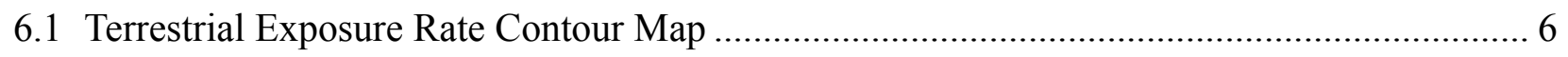

6.2 Man-Made Gross Counts Map............................................................................................ 6

6.3 Ra-226 (Bi-214) Extracted Isotope Counts Map …………………………....................... 10

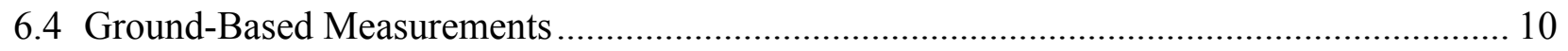

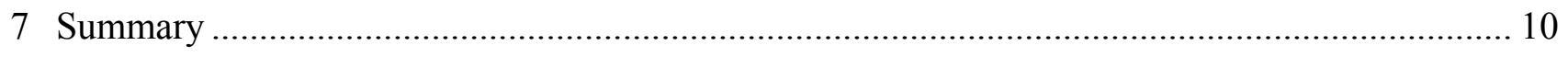

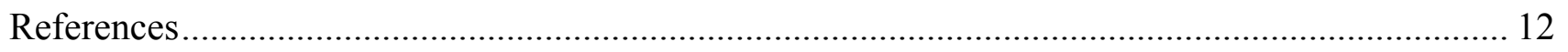




\section{Appendices}

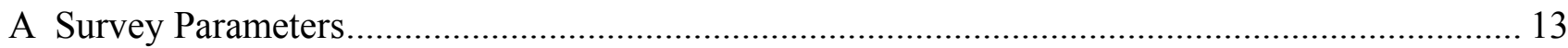

B Ground-Based Measurements Compared to Inferred Aerial Measurements ............................ 14

\section{Figures}

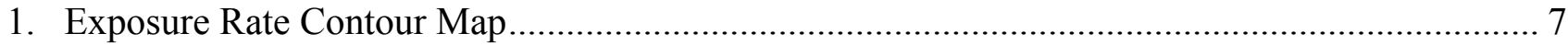

2. MMGC Exposure Rate Map with Locations of Seven Spectral ROIs Noted............................. 8

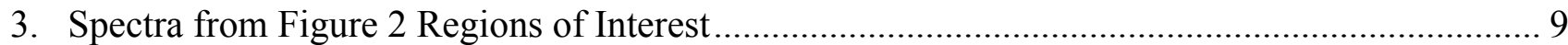

4. Bismuth-214 Exposure Rate Map ............................................................................... 10 


\section{ACRONYMS AND ABBREVIATIONS}

$\begin{array}{ll}\text { AGL } & \text { above ground level } \\ \text { AMS } & \text { Aerial Measuring System } \\ \text { Bi-214 } & \text { bismuth-214 } \\ \text { cps } & \text { counts per second } \\ \text { DGPS } & \text { differential Global Positioning System } \\ \text { DOE } & \text { U.S. Department of Energy } \\ \text { ER } & \text { exposure rate } \\ \text { K-40 } & \text { potassium-40 } \\ \text { MMGC } & \text { man-made gross count } \\ \text { NaI(Tl) } & \text { thallium-activated sodium-iodine } \\ \text { Pa-234m } & \text { protactinium-234m } \\ \text { PIC } & \text { pressurized ionization chamber } \\ \text { RA } & \text { radar altimeter } \\ \text { Ra-226 } & \text { radium-226 } \\ \text { RAP } & \text { Radiological Assistance Program } \\ \text { REDAR-V } & \text { Radiation and Environmental Data Acquisition and Recorder, Version V } \\ \text { ROI } & \text { region of interest } \\ \text { RSL-A } & \text { Remote Sensing Laboratory-Andrews } \\ \text { USGS } & \text { United States Geological Survey } \\ \mu \text { R/h } & \text { microroentgens per hour }\end{array}$




\section{INTRODUCTION}

An aerial radiological survey of the Portsmouth Gaseous Diffusion Plant, Portsmouth, Ohio, was conducted from August 7 to August 8, 2007, at the request of the U.S. Department of Energy (DOE). The survey covered a region of $4.5 \times 3.5$ miles $(\sim 7.2 \times 5.6$ kilometers $)$ for a total area of 16 square miles ( $\sim 41$ square kilometers) surrounding the Portsmouth plant. The survey was conducted by a team from the DOE's Remote Sensing Laboratory-Andrews (RSL-A), maintained and operated by National Security Technologies, LLC, in Washington, D.C.

The primary purpose of the survey was to update the previous radiological surveys levels of the Portsmouth plant and surrounding areas. ${ }^{1,2,3,4}$. A search for a missing 22.5 millicurie radium-226 (Ra-226) source that was to be shipped to the Nevada Test Site for disposal was also performed. During March 2-4, 2007, the DOE Radiological Assistance Program (RAP) region 2 responded to the Portsmouth plant to search for the missing source. The RAP team was not successful in locating the source, but their work increased the level of confidence that the source is not located within the immediate plant confines. The RSL-A aerial survey was intended to extend the areas covered by the RAP team and provide maps of the total, man-made, and radium-specific activity present in the extended area outside of the immediate plant.

The data were collected by the Aerial Measuring System (AMS) Radiation and Environmental Data Acquisition and Recorder, Version V (REDAR-V) using an array of twelve $2 " \times 4 " \times 16^{\prime \prime}$ sodium iodide detectors flown onboard a twin-engine Bell 412 helicopter. The data were geo-referenced using a differential Global Positioning System (DGPS). Gamma energy spectra were collected every second during the survey. This spectral data allows the system to distinguish between ordinary fluctuations in natural background radiation levels and signatures produced by man-made isotopic sources. Spectral data can also be used to identify specific radioactive isotopes.

The current survey data is in substantial agreement with previous surveys of the Portsmouth Gaseous Diffusion Plant and surrounding area. $1,2,3,4$

\section{SURVEY SITE DESCRIPTION}

The Portsmouth plant is located on a large, government-owned reservation near Piketon, Ohio, about 20 miles ( $\sim 32$ kilometers) north of Portsmouth, Ohio, and 78 miles ( $\sim 126$ kilometers) south of the state capital of Columbus. The plant is located 2 miles ( 3.2 kilometers) east of the Scioto River. The Portsmouth plant consists of a 7 square mile ( $\sim 18$ square kilometer) fenced area with an average elevation of 675 feet ( 206 meters) above sea level. The area surrounding the plant is primarily forest and farm land. 


\section{SURVEY PROCEDURE}

\subsection{Aerial Survey}

The aerial survey collected gamma radiation data over a 16 square mile ( $\sim 1$ square kilometer) area around the Portsmouth plant. Major roads servicing the Portsmouth facility, as well as the facility perimeter, were taken into consideration when defining the survey boundaries.

The area was surveyed at a nominal ground speed of 70 knots ( $~ 36$ meters per second), at 150 feet ( 46 meters) above ground level (AGL), along a parallel set of flight lines spaced 250 feet ( $\sim 76$ meters) apart, totaling approximately 338 flight line miles ( $\sim 544$ flight line kilometers). The flight lines were flown in a southerly or northerly direction. All data were scaled to overlay a United States Geological Survey (USGS) topographic survey map. To assure data integrity and to monitor/correct for variations in detector background count rate due to aircraft, radon, and cosmic rays, repeated measurements were made over a fixed test line before and after each flight. The fixed test line was located next to Greater Portsmouth Regional Airport runway.

\subsection{Ground-Based Measurements}

Ground-based pressurized ionization chamber (PIC) measurements were acquired at six locations within the survey area and three locations on the fixed test line. These measurements were taken to provide comparative exposure rates and support the integrity of the aerial data. The PIC measurements were averaged over a period of approximately 15 minutes at a height of 1 meter AGL.

\section{SURVEY EQUIPMENT}

\subsection{Aerial Survey}

The aerial survey was conducted using AMS helicopter. The detection system consists of a Bell-412 helicopter, a REDAR-V system, a Trimble DGPS and two large detector pods externally mounted on each side of the helicopter. Each pod contained six $2^{\prime \prime} \times 4^{\prime \prime} \times 16^{\prime \prime}$ thallium-activated sodium-iodine, $\mathrm{NaI}(\mathrm{Tl})$, gamma ray detectors.

\subsubsection{Data Recording}

The preamplifier signal from each detector was calibrated using naturally occurring potassium-40 (K-40) and americium-241 (Am-241) gamma check sources. Normalized outputs from 12 large detectors were combined in a summing amplifier, and the signal was adjusted in the analog-to-digital converter so that the calibration photopeaks appeared in preselected channels in the REDAR-V multichannel analyzer. The data from the multichannel analyzer were used to produce second-bysecond records containing the number of gamma rays detected at each specific gamma-ray energy. Each record, therefore, constitutes a specific gamma-ray spectrum. As every radioactive material, natural or man-made, has its own unique set of gamma rays, spectra can be used to identify and separate sources of detected gamma radiation. 
The REDAR-V, which produces the gamma-ray spectra described above, is a multi-processor data acquisition and real-time analysis system custom-designed by the Remote Sensing Laboratory to operate in the severe environments associated with platforms such as helicopters, fixed-wing aircraft, and various ground-based vehicles. The system displays radiation and positional information in real time to the operator via video displays and multiple digital readouts. Archival gamma-ray spectra, aircraft position, meteorological parameters, real-time clock, and other data reference information are recorded at one-second intervals on digital data storage devices for postflight analyses.

\subsubsection{Helicopter Positioning}

The helicopter's position was measured by using two systems: a Trimble DGPS (utilizing OmniSTAR differential corrections) and a radar altimeter (RA). The DGPS provides continuous position information using a constellation of 24 satellites. The DGPS has a horizontal positional accuracy ( 1 sigma) of \pm 1 meter ( 3 feet). The RA determines the helicopter's altitude by measuring the round-trip propagation time of a signal reflected off the ground. The manufacturer's nominal accuracy of the RA is quoted as 2 feet or $2 \%$, whichever is greater.

\subsubsection{Data Processing}

For each flight, the aerial survey data were downloaded for processing from an Iomega zip drive into the PC-based Radiation and Environmental Data Analysis Computer system. This system provided onsite preliminary analysis of the aerial data on a flight-by-flight basis and monitored pre- and postflight quality assurance checks.

\subsection{Ground-Based Measurements}

Ground level exposure rate measurements were acquired at the Portsmouth Plant using a ReuterStokes PIC. This instrument is portable and battery-powered. It incorporates a 25 centimeter (10 inch) diameter metal sphere filled with 25 atmospheres of Argon gas, a high voltage bias supply, an electrometer, and readout components. This unit has a sensitivity of $\sim 3 \times 10^{-14}$ amps per microroentgens per hour $(\mu \mathrm{R} / \mathrm{h})$ and has the capability of digitally and graphically displaying the total exposure rate data. The ground measurements were used to compare to the exposure rates inferred by the aerial measurements. 


\section{ANALYSIS PROCEDURES}

\subsection{Aerial Data Analysis}

The aerial radiation data have contributions from the naturally occurring radionuclides, man-made radionuclides, airborne radon, cosmic rays, and radioactive materials present in the aircraft. Contour maps were produced by processing the aerial data using extraction methods discussed in this section. More detailed mathematical steps are discussed in the previous survey report. ${ }^{1}$

\subsubsection{Terrestrial Exposure Rate}

The terrestrial exposure rate was derived from the integral counting rate in the gamma energy spectrum range between 38 and 3,026 keV. This count rate, measured in counts per second (cps) at survey altitude, is converted to exposure rate (ER) in $\mu \mathrm{R} / \mathrm{h}$ at 1 meter AGL by using the following equation:

$$
E R(\mu R / h)=\frac{G C-B}{1712} \cdot e^{(A-150) \cdot C}
$$

where

$\mathrm{GC}=$ gross count rate at survey altitude $(\mathrm{cps})$

$\mathrm{B}=$ background count rate at survey altitude (cps)

$\mathrm{A}=$ Distance above ground level from RA (feet)

$\mathrm{C}=$ gamma ray air attenuation coefficient $\left(\right.$ feet $\left.^{-1}\right)$

The background count rate (B), determined initially from the test line altitude profile and adjusted on a flight-by-flight basis, consists of cosmic rays, the aircraft system, and airborne radon. The air attenuation coefficient, $\mathrm{C}$, also determined from the test line data, was $0.001761 \mathrm{feet}^{-1}(0.005778$ meter $\left.^{-1}\right)$. The conversion factor $(1,712 \mathrm{cps} / \mu \mathrm{R} / \mathrm{h}$ ) for 150 feet (46 meters) AGL was determined from documented calibration test lines located in Calvert County, Maryland. ${ }^{5}$ The conversion factor assumes a uniformly distributed radiation source: 1) covering an area that is a large when compared to the field of view of the detector system (a circle with a diameter roughly twice the altitude of the aircraft), and 2) having a gamma-ray energy distribution similar to that of the natural background of the calibration test line.

\subsubsection{Man-Made Gross Count}

The aerial data were also used to determine the location of man-made radionuclides. The man-made gross count (MMGC) is the portion of the gross count that is directly attributed to the gamma rays from the man-made radionuclides. In general, evidence of man-made radionuclides can be found from increases in the gross count rate. However, slight variations in the gross count do not always indicate the presence of a man-made anomaly, since these variations can result from geological fluctuations or changes in the ground coverage (e.g., river, dense vegetation, buildings). 
In order to increase the sensitivity to detect man-made anomalies, an MMGC algorithm has been developed that uses spectral energy extraction techniques to detect man-made activity. This algorithm takes advantage of the fact that while background radiation levels often vary by a factor of two or more within a survey area, background spectral shapes remain essentially constant. More specifically, the ratio of natural components in any two regions (windows) of the energy spectrum will remain nearly constant.

Although this procedure can be applied to any region of the gamma energy spectrum, for general man-made activity, common practice is to place all counts below 1,394 keV into the man-made window (low energy sum), where most of the long-lived, man-made radionuclides emit radiation, and to place all counts above 1,394 keV into the natural window (high energy sum), where mostly the naturally occurring radionuclides emit radiation. The MMGC rate can be expressed analytically in terms of the integrated count rates in specific gamma energy spectral windows $(\mathrm{keV})$ :

$$
M M G C=\sum_{E=38}^{1394} S(E)-K_{m m} \cdot \sum_{E=1394}^{3026} S(E)
$$

where $\mathrm{K}_{\mathrm{mm}}$ is measured over an area that only contains gamma radiation from naturally occurring radionuclides as

$$
K_{m m}=\frac{\sum_{E=38}^{1394} S(E)}{\sum_{E=1394}^{3026} S(E)}
$$

This MMGC algorithm is sensitive to low levels of man-made radiation even in the presence of large variations in the natural background. When man-made radioactivity has been identified, a detailed analysis of the gamma energy spectrum is conducted to ascertain which radionuclides are present.

\subsubsection{Radium-Specific Isotope Extraction Algorithm}

The Ra-226 source will show a photopeak at 1,764 keV (from bismuth-214 [Bi-214] in the Ra-226 decay chain). The variable natural background also contributes to that photopeak. A spectrum-based algorithm can remove the variable background contribution in a second-by-second operation. The resulting data has a statistical distribution of counts centered around a net value of zero in regions of background-only. If a statistically significant source is present, its activity will show up as an excursion above the statistical bounds associated with the natural background activity.

The form and function of the radium extraction algorithm is identical to the MMGC algorithm presented in Section 5.1.2 with spectral windows reset for the specific extraction of the Ra-226 (Bi-214) source contribution. The source energy window was reset to 1,574 through 1,946 keV. The background energy window was reset to 2,342 through $2,882 \mathrm{keV}$. 


\subsection{Ground-Based Measurements}

PIC measurements were collected at a height of 1 meter AGL at six locations within the survey area and three locations on the test line. Most of these locations were not near any obvious radiation anomalies. The measurements were collected to compare to the inferred aerial radiological exposure rate results. These PIC spot checks were too few in number and too limited in background dynamic range to be utilized in the derivation of the exposure rate calibration for the system.

\section{RESULTS}

\subsection{Terrestrial Exposure Rate Contour Map}

Figure 1 displays the terrestrial-only gamma exposure rate inferred from the aerial data in the form of a color-fill contour map superimposed on a USGS map. Processing of the aerial measurement data removes cosmic, radon, and aircraft contributions. The map shows high levels of radiation at the locations identified as cylinder yards within the plant. Over most of the survey area, the inferred exposure rates range from 1 to $9 \mu \mathrm{R} / \mathrm{h}$ and are typical for natural background in the Portsmouth area. The background exposure rates are in good agreement with previous survey data. ${ }^{1}$ Lower exposure rates are seen at the depleted uranium storage area (high counts area) than were seen in the previous survey.

\subsection{Man-Made Gross Counts Map}

The MMGC algorithm (discussed in the Section 5.1.2) was used to study the aerial data for manmade radionuclides in the survey area. The MMGC map (Figure 2) shows the activity that is attributable to gamma radiation from man-made radioisotopes with the variable natural background component removed.

Figure 2 also shows the locations of seven regions of interest (ROIs). Spectral data were extracted from each ROI. This map shows man-made activity in the cylinder yards and in one small area designated as ROI 7. The region designated as ROI 7 was not present in the previous survey.

Figure 3 shows the gamma energy spectra extracted from the seven ROIs. The spectra all show evidence of protactinium-234m (Pa-234m), which is a decay product of uranium-238. 


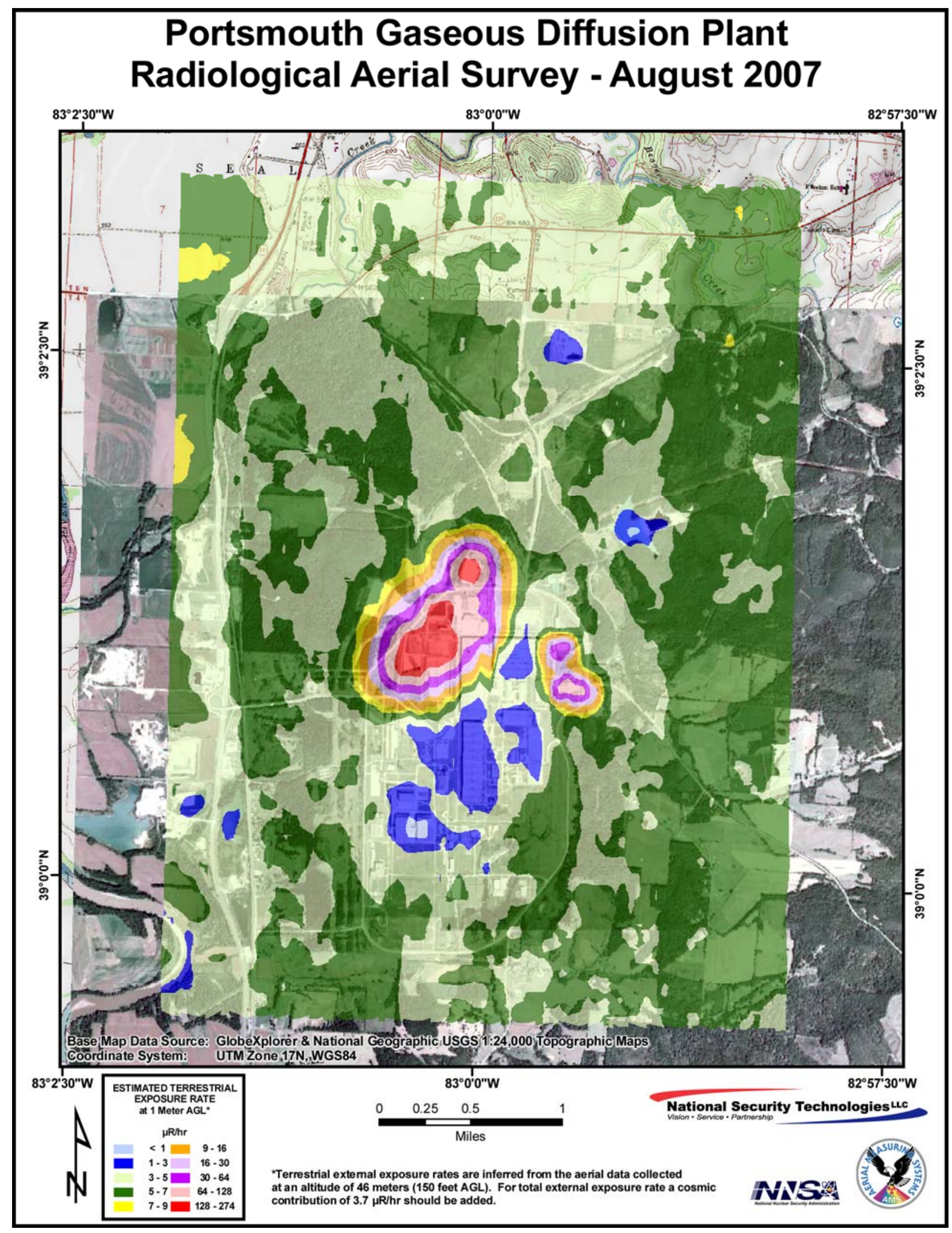

Figure 1. Exposure Rate Contour Map 


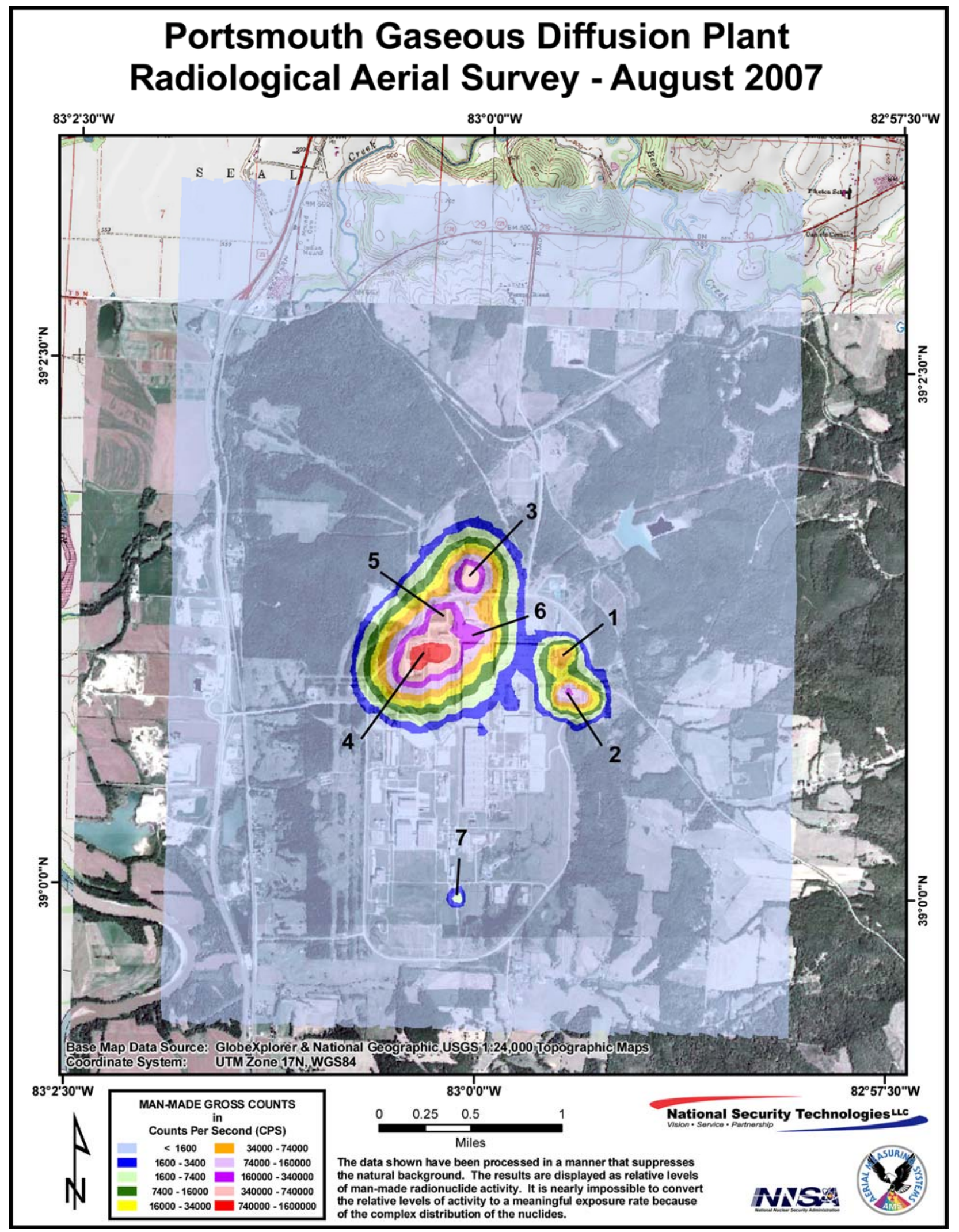

Figure 2. MMGC Exposure Rate Map with Locations of Seven Spectral ROIs Noted 

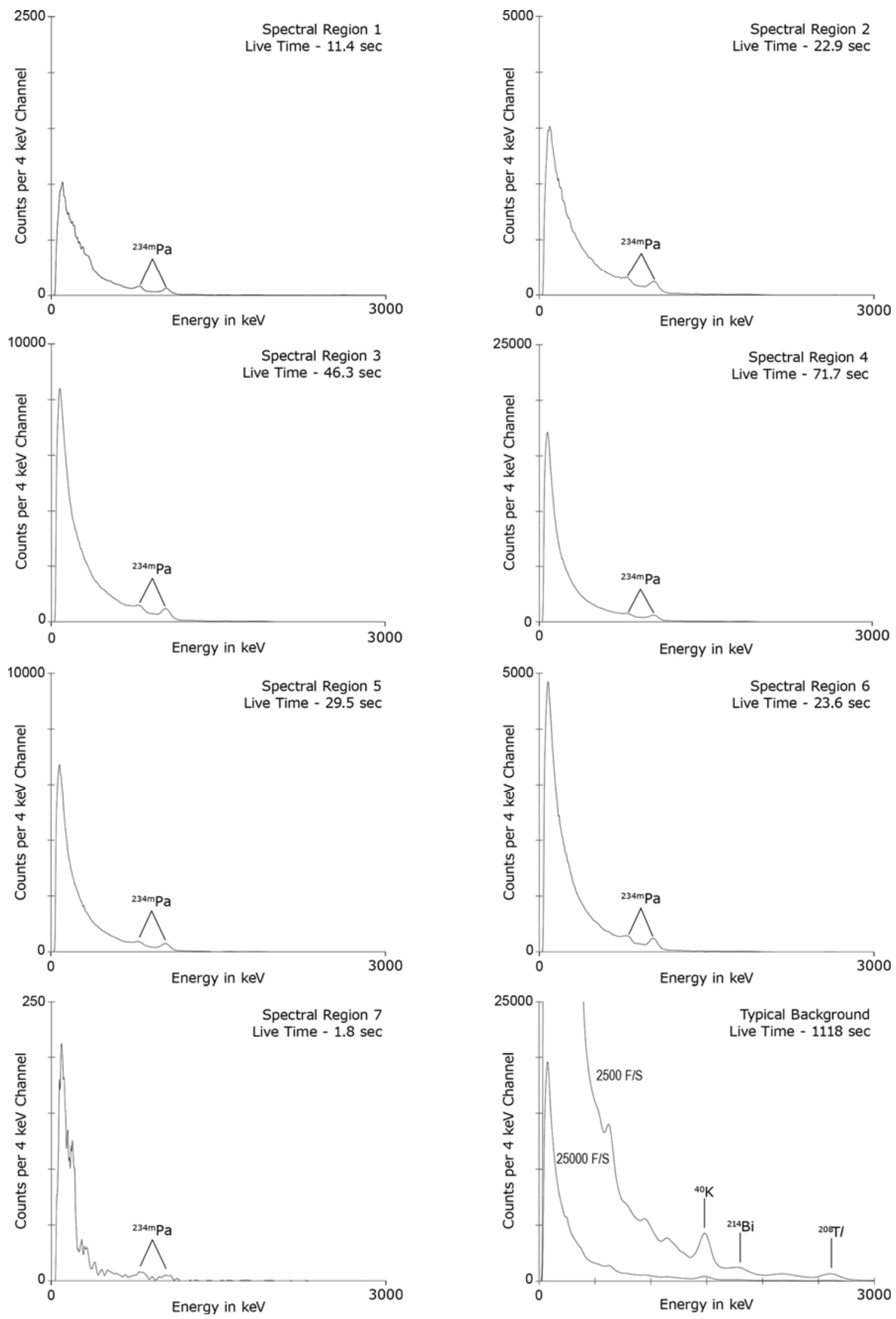

Figure 3. Spectra from Figure 2 Regions of Interest 


\subsection{Ra-226 (Bi-214) Extracted Isotope Counts Map}

The radium specific isotope extraction algorithm (discussed in Section 5.1.3) was used to study the aerial data for the possible presence of the lost Ra-226 source in the survey area. The rose-colored region of Figure 4 is where pulse pileup from the $\mathrm{Pa}-234 \mathrm{~m}$ photopeaks distorted the spectral data to the extent that the Ra-226 (Bi-214) algorithm could no longer produce meaningful data. The most likely value of the observed Ra-226 activity was zero counts per second (as expected) with a statistical uncertainty of $\pm 25 \mathrm{cps}$ ( 1 sigma). There were no statistically significant values (values greater than 3 sigma) found by the algorithm. Plot levels in Figure 4 were set at \pm 2 sigma (well into the uncertain value range) to see if potential source information might be seen in the noise patterns. Negative statistical values between the levels of -3 to -2 sigma are shown in black, positive statistical values between the levels of 2 to 3 sigma are shown in blue. Activity seen in these lower sigma ranges can likely be attributed to statistical variation.

\subsection{Ground-Based Measurements}

Ground-based measurements are compared to inferred aerial measurements in Appendix B. The spread between PIC and aerial measurements is quite acceptable, being a maximum of $1.2 \mu \mathrm{R} / \mathrm{h}$ for background regions. Measurements taken in regions of high man-made activity are not expected to compare well, since the aerial system and the ground system have significantly different measurement footprints.

\section{SUMMARY}

Total exposure rate and man-made count rate activity for the site were documented. The current survey data indicate that there has been no significant change from the previous surveys. No evidence of the missing source was found in the major portions of the survey. However, the strong depleted uranium signature at the cylinder yards would have prevented the detection of the missing Ra-226 source if it were located in the high count-rate areas. 


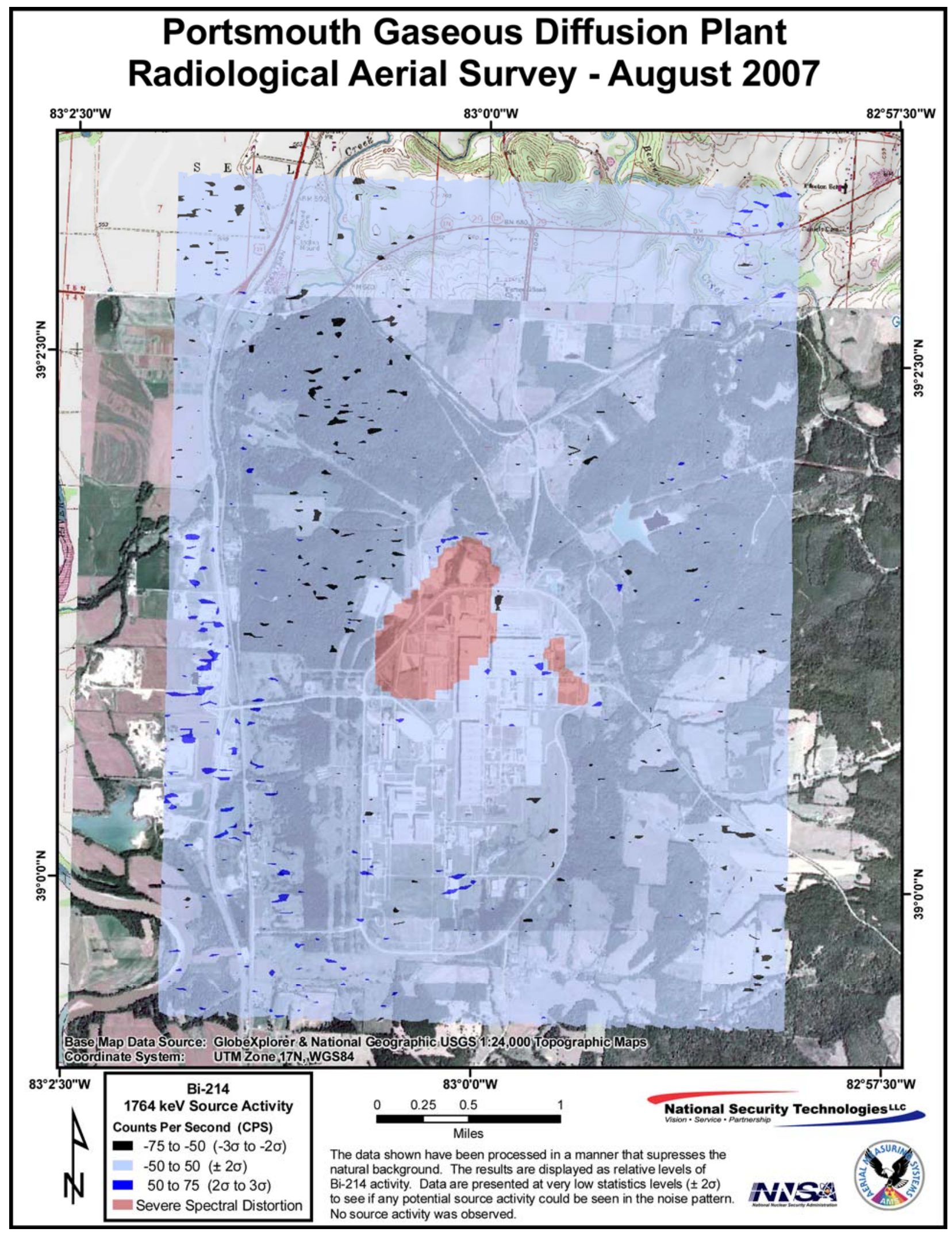

Figure 4. Bismuth-214 Exposure Rate Map 


\section{REFERENCES}

1. Sampoll-Ramirez, G. An Aerial Radiological Survey of the Portsmouth Gaseous Diffusion Plant and Surrounding Area, Date of Survey: August 1993, EG\&G/EM Report No. EGG 11265-1085, Las Vegas, Nevada, 1994.

2. Guss, P. P.,An Aerial Radiological Survey of the Portsmouth Gaseous Diffusion Plant and Surrounding Area, Date of Survey: July 1990, EG\&G/EM Report No. EGG-10617-1154, Las Vegas, NV, 1992.

3. Colton, D. P., An Aerial Radiological Survey of the Portsmouth Uranium Enrichment Plant, Date of Survey: May 1984, EG\&G/EM Report No. EGG-10282-1081, Las Vegas, Nevada, 1985.

4. Feimster, E. L.,An Aerial Radiological Survey of the Area Surrounding the Portsmouth Gaseous Diffusion Plant, Date of Survey: July 1976, EG\&G/EM Report No. EGG-1183-1719, Las Vegas, Nevada, 1979.

5. Mohr, R. A., Ground Truth Measurements at the Calvert County, Maryland Test Line, EG\&G/EM Report No. EGG-10282-2066, Santa Barbara, California, 1985. 


\section{APPENDIX A SURVEY PARAMETERS}

Survey Site:

Survey Coverage:

Survey Date:

Survey Altitude:

Aircraft Speed:

Line Spacing:

Navigation System:

Line Direction:

Detector Configuration:

Acquisition System:

Conversion Factor:

Air Attenuation Coefficient:

Aircraft:

Project Scientist:

Data Analyst:

Electronic Technicians:

Helicopter Pilots:

Aviation Mechanic:
Portsmouth Gaseous Diffusion Plant, Piketon, Ohio

16 square miles ( $\sim 41$ square kilometers)

August 7-8, 2007

150 feet ( $\sim 6$ meters)

70 knots ( $\sim 36$ miles per second)

250 feet ( $\sim 6$ meters)

Trimble DGPS (OmniSTAR corrections) differential

North-South

Twelve $2^{\prime \prime} \times 4^{\prime \prime} \times 16^{\prime \prime} \mathrm{NaI}(\mathrm{Tl})$ detectors

REDAR-V

$1,712 \mathrm{cps} / \mu \mathrm{R} / \mathrm{h}$

$0.001761 /$ feet $(0.005778 /$ meters $)$

Bell-412 Helicopter

Namdoo Moon

Jezabel Stampahar

Kevin Borders

Michael Lukens

Timothy Rourke

Emanuel Avaro

Ed Zachman 


\section{APPENDIX B \\ GROUND-BASED MEASUREMENTS COMPARED TO INFERRED AERIAL MEASUREMENTS}

\begin{tabular}{|c|c|c|c|c|c|c|c|c|c|}
\hline $\begin{array}{l}\text { Ref } \\
\text { Point }\end{array}$ & $\begin{array}{l}\text { Latitude } \\
\text { (degrees) }\end{array}$ & $\begin{array}{l}\text { Longitude } \\
\text { (degrees) }\end{array}$ & $\begin{array}{c}\text { PIC } \\
\text { Total } \\
(\mu R / h)\end{array}$ & $\begin{array}{c}\text { PIC } \\
\text { Terrestrial } \\
(\mu \mathrm{R} / \mathrm{h})\end{array}$ & $\begin{array}{c}\text { PIC } \\
\text { Counting } \\
\text { Uncertainty }\end{array}$ & $\begin{array}{c}\text { Aerial } \\
\text { Terrestrial } \\
\text { (cps) }\end{array}$ & $\begin{array}{c}\text { Aerial } \\
\text { Terrestrial } \\
(\mu \mathrm{R} / \mathrm{h})\end{array}$ & $\begin{array}{c}\text { Aerial } \\
\text { Data } \\
\text { Multipoint } \\
\text { Variability } \\
(\mu \mathrm{R} / \mathrm{h})\end{array}$ & $\begin{array}{l}\text { PIC to } \\
\text { Aerial } \\
\text { Spread } \\
(\mu R / h)\end{array}$ \\
\hline $0^{*}$ & 38.83442 & -82.84646 & 9.4 & 4.7 & 0.5 & 6810 & 4.0 & 0.1 & 0.7 \\
\hline $1 *$ & 38.83686 & -82.84656 & 10.4 & 5.7 & 1.4 & 7890 & 4.6 & 0.1 & 1.1 \\
\hline $2^{*}$ & 38.84329 & -82.84692 & 10.8 & 6.1 & 0.5 & 8413 & 4.9 & 0.1 & 1.2 \\
\hline 3 & 39.00800 & -82.99700 & 9.5 & 4.8 & 0.5 & 6149 & 3.6 & 0.2 & 1.2 \\
\hline 4 & 39.00740 & -83.00759 & 7.1 & 2.4 & 0.4 & 3408 & 2.0 & 0.7 & 0.4 \\
\hline 5 & 39.01937 & -83.00248 & 70.1 & 65.4 & 0.7 & 201320 & 117.6 & 30.9 & -52.2 \\
\hline 6 & 39.02222 & -82.99934 & 44.9 & 40.2 & 0.7 & 83514 & 48.8 & 12.9 & -8.6 \\
\hline 7 & 39.00807 & -83.00203 & 8.1 & 3.4 & 0.5 & 4540 & 2.7 & 0.2 & 0.7 \\
\hline 8 & 39.04659 & -83.02846 & 10.0 & 5.3 & 0.5 & 10090 & 5.9 & 0.3 & -0.6 \\
\hline
\end{tabular}

* Reference points 0,1 , and 2 are taken along the test line.

Measured PIC data intrinsically includes cosmic and radon contributions.

Estimated values of 3.7 and $1.0 \mu \mathrm{R} / \mathrm{h}$ respectively were removed from measured PIC to get terrestrial.

Measured Aerial data utilized altitude profile information to remove cosmic and radon contributions.

Aerial test line average counts were used to compare to PIC test line measurements.

Points 5 and 6 were taken in areas where exposure rate was very different for points within the examined area.

Yellow columns indicate source and results of PIC and aerial comparisons 